\title{
Training access services staff to partner in digital projects metadata creation
}

W

ith thousands of images already scanned but completely hidden from public view, archivists and librarians at University of North Carolina (UNC)-Charlotte's J. Murrey Atkins Library needed innovative, efficient ways to describe these digital objects and make them available to patrons through search and discovery. Budget conditions prevented hiring additional personnel and challenged library managers to think creatively to use existing library staff. Managers also sought to maximize downtime while expanding staff members' current knowledge and professional experience.

This article examines the collaborative endeavors of the Special Collections Department and the Access Services Unit to train service desk staff to create robust Dublin Core metadata records for digital objects (photographs, postcards, historic documents, maps, oral histories) included in the Digital Collections at Atkins Library. The three main topic areas will include: 1) staff training and access services desk work flow; 2) challenges (authority control, quality control, inter-indexer consistency); and 3) evaluation of the project and plans for the future.

The unique training and work flow procedures we created) can serve as a model for other libraries that seek to refocus the professional efforts of existing staff and provide comprehensive access to previously hidden materials.

UNC-Charlotte is North Carolina's urban research university, located in the state's largest metropolitan area with an enrollment of more than 25,000 students. UNC-Charlotte is among the fastest growing universities in the 16-campus University of North Carolina System. The university maintains a particular commitment to addressing the cultural, economic, educational, environmental, health, and social needs of the greater Charlotte region. ${ }^{1}$

The Special Collections Unit at Atkins Library comprises seven librarians and archivists and five staff members. Student workers are hired each semester to assist with digital production and have served as a valuable resource for scanning and providing basic description of digital objects for Digital Collections. However, a large backlog of digital items exists, most of which lack description and are therefore unable to be accessed by the public. In addition, student workers often lack the experience and training to create substantial, robust metadata records.

Special Collections developed this large digital backlog for more than ten years for several reasons. Patrons have requested high-resolution digital images for a variety of reasons, including publications and research. Librarians and archivists also digitally reproduced some photographic collections as a preservation measure; certain kinds of film are fragile and susceptible to disintegration, and scanning was used to preserve the content before the film deteriorated. Consequently, nearly 10,000 digital images were created or acquired,

Kristy L. Dixon is head of digital programs and special collections, e-mail: kdixon21@uncc.edu, and Lisa T. Nickel is head of access services, e-mail: lisa.nickel@ uncc.edu, at J. Murrey Atkins Library at the University of North Carolina-Charlotte

() 2012 Kristy L. Dixon and Lisa T. Nickel 
none of which had descriptive metadata attached to them.

To address this backlog, Special Collections collaboated with the Access Services Unit. Access Services consists of four departments with 16 FTE staff: Inter-Library Loan, Circulation, Reserves, and Stacks Maintenance. These departments have cyclical patterns in which demands on their time and skills vary widely. Staff members are often very busy during the fall and spring semesters; during interim periods and summer semester, they have ample time to contribute to other projects. The staff members in Access Services understand and create some library records (particularly in reserves) and are familiar with cataloging concepts, but cataloging has never been a component of their jobs. Thus, they are not necessarily experts at Library of Congress (LC) subject headings, deep subject analysis, or metadata schemas, particularly non-MARC metadata.

\section{Group workshops}

The digital programs archivist held four onehour open training workshops in which she presented an overview of the project and explained how the Access Services contributions would help the library by increasing the visibility of its digital collections. In these training sessions, the digital archivist presented the current digital collections that have been fully described and made public through CONTENTdm, the digital asset management system used at Atkins Library. She highlighted specific digital images and their corresponding Dublin Core metadata records. She then gave a detailed explanation of the Dublin Core metadata schema and defined the parameters for each of the 16 fields used for digital object metadata within Digital Collections at Atkins Library.

The workshops focused heavily on two aspects of metadata creation: subject analysis and writing descriptions.

\section{Subject analysis training}

Subject analysis involves examining the item being described and applying appropriate subject headings through the identification of people, objects, locations, buildings, materials, and events as well as intellectual concepts and themes represented by the item. This can be an issue for library staff who have never had training or experience in cataloging digital materials.

Difficulties and confusion can surround the practice of subject analysis for several reasons.

- It is subjective; one person may interpret different themes and see different objects in the items he or she is cataloging.

- Subject analysis of digital objects (still images, audio, moving images) differs from traditional cataloging in that the cataloger does consider aesthetics when creating metadata for digital objects as well as philosophical and intellectual themes.

- Creating metadata for digital objects requires the person cataloging the item to strike a balance between traditional subject analysis and indexing. That is, providing enough detailed information for end users to find materials for which they are looking while not devoting excessive time and resources to a single item.

Digital Collections at Atkins Library employs controlled vocabularies for subject headings, such as Library of Congress Subject Headings (LCSH), Library of Congress Thesaurus of Graphic Materials (TGM), the Getty Art and Architecture Thesaurus (AAT), and Library of Congress Name Authority File (LCNAF). Subject analysis training included an overview of each of these vocabularies and basic rules for applying subject headings. The workshops also covered the resources themselves and strategies for effectively searching the vocabularies to find appropriate headings.

\section{Writing descriptions}

The digital archivist provided an overview of writing descriptions for the <dc:description $>$ field in a Dublin Core (DC) metadata record. The staff participated in exercises in which images were displayed on an overhead projector, and each participant wrote short descriptions. The group then shared 
and discussed the descriptions, comparing them to each other's and to the description guidelines.

\section{One-on-one training}

The digital archivist also conducted several "roaming metadata help" sessions. She was available to anyone for one-on-one advisement/training/observation during scheduled two-hour periods. During those times, she visited the Access Services Unit offices and notified staff that meeting times were available at any time during those two hours. Staff geographic subdivisions. To alleviate confusion and foster interindexer consistency, the digital archivist added a tab on each staff member's metadata entry spreadsheet preloaded with thousands of formed LCSHs. This way, staff could browse and choose headings often used in local collections without having to learn the complex rules of precoordination. Staff were invited to create subject headings if necessary, but each new term needed to be reviewed and approved by the digital archivist for entry into the local controlled vocabulary.

members responded positively and enthusiastically to the training sessions. One advantage to this kind of training is the opportunity to engage with staff members on an individual level. One-on-one meetings also allowed each staff member to communicate his or her areas of interest

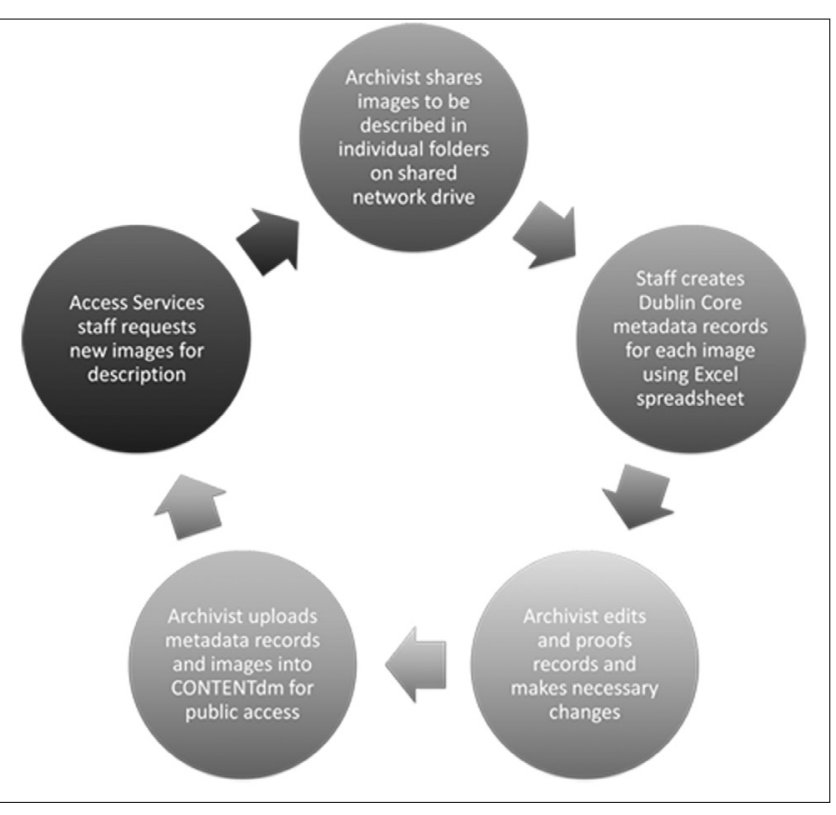

Descriptions -challenges and solutions

The styles of description varied greatly from one staff member to another. Some individuals focused on details within the digital images and wrote very extensive, cohesive descriptions. Metadata creation project workflow. Several staff memand expertise, which allowed the digital archivist to consider those factors when assigning collections to individuals.

The individual meetings helped the digital archivist gather information about each staff member's strengths and weaknesses, and perceptions of description and metadata creation.

\section{LCSH-challenges and solutions}

Some staff demonstrated a keen understanding of searching for LCSH through Classification Web and using geographic subdivisions. However, some did not feel comfortable creating precoordinated subject headings or

bers typically wrote brief, single-phrase or single-sentence descriptions and often did not provide much more information in the $<$ dc:description $>$ field than they provided in the <dc:title $>$ field. Ongoing training continues to address these discrepancies and encourage staff members to find the balance between too little and too much.

\section{Gauging confidence}

The digital archivist and head of Access Services closely observed staff members throughout the training to gauge confidence and encourage staff with positive feedback. Some staff members expressed anxiety about 
doing it "right" and seemed unsure of themselves and their work. This was dealt with by offering more training times and one-on-one sessions with the digital archivist to reinforce the new skills and practice creating metadata records with immediate feedback. Also, the digital archivist regularly communicated with Access Services staff through e-mail and established an "open-door" policy to assure staff that questions were always welcome.

\section{Technical difficulties}

At the time this project began, Atkins Library's CONTENTdm license level only allowed three project clients in the building; these clients were designated for the digital archivist and two metadata catalogers. Consequently, the digital archivist could not load images directly into CONTENTdm for Access Services staff to catalog and upload for approval.

The authors were challenged to think creatively and decided to use the library's shared network drive and created new folders for each Access Services staff member who held newly created metadata entry spreadsheets, images for description, and any additional documentation needed to complete the metadata (fact sheets, articles, finding aids, etc.). Excel spreadsheets provide adequate means for creating and storing metadata, and they work especially well if an institution does not have a digital asset management system in place. Although using spreadsheets for metadata descriptions is a reasonable process to enact, there are a few drawbacks:

- Loading metadata from spreadsheets is somewhat time and labor intensive for the digital archivist.

- Spreadsheets do not include the built-in quality control features that the CONTENTdm Project Client does, such as controlled vocabulary verification, date format standardization, and highly customizable field properties.

- Rather than loading the images directly into CONTENTdm for the Access Services staff to see, large collections of images were copied into the individual folders on the shared drive. The huge file sizes (many of the images are TIFFs) take a great deal of time to copy, and the shared drive has finite memory - these images can potentially fill up a drive quickly.

\section{Retraining necessary}

In May 2011, Atkins Library purchased the next license level of CONTENTdm. The number of project clients available for use grew from three to 50 . This brings many benefits to the project, as the steps of metadata entry into spreadsheets and manually transferring images from folder to folder and then into CONTENTdm will be eliminated. However, it also means that all Access Services staff will need to be retrained in a new system. This could be potentially time-consuming for all involved, and it could also cause anxiety to individuals who may feel some discomfort learning new computer programs and tools.

\section{Assessment/analysis}

This project will be evaluated on an on-going basis through both qualitative and quantitative data. As the project is in its infancy, little data has been collected. However, the project will be evaluated through the following means:

- surveys given to Access Services staff to measure perceptions of and satisfaction with training, ongoing support, and workload;

- surveys given to library faculty and staff to measure perceptions of cross-departmental collaboration and resulting work quality; and

- numbers of items described by Access Services staff (as of 6/22/2011, 450 images have been fully described)

The evaluation will include, but may not be limited to, these particular measures. As the project evolves, the assessment tools will likely change to reflect the direction of the project.

\section{Plans for the future}

We plan to continue this collaboration between Special Collections and Access Services for the foreseeable future. Future plans include:

(continues on page 82) 


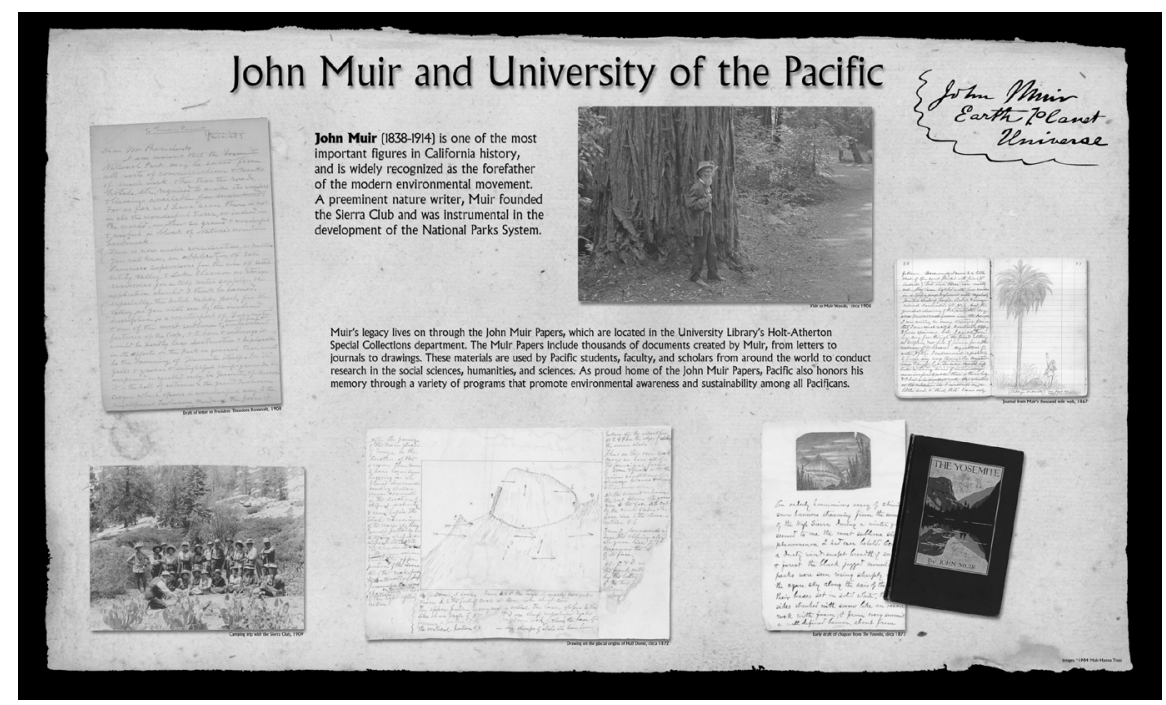

John Muir Papers poster. The poster on John Muir and University of the Pacific makes clear the links between the Muir Woods photograph and the University Library's John Muir Papers. View this article online for detailed image.

certainly an exercise in collective imagination that extended well beyond the library's walls to raise the visibility of the John Muir Papers, while enhancing the aesthetic appeal of the study commons.

\section{Notes}

1. Information on the John Muir Papers can be found at http://library.pacific.edu/ha/muir/.
2. James Rettig, "Art for Everyone's Sake," Virginia Libraries 50, no. 3 (2004): 5.

3. Bonnie Johanna Gisel and Stephen J. Joseph, Nature's Beloved Son: Rediscovering John Muir's Botanical Legacy (Berkeley, Calif.: Heyday Books, 2008).

4. John Muir, "The National Parks and Forest Reservations," Sierra Club Bulletin 1, no. 7 (1896): 283. $n$
("MetaWHAT?" cont. from page 77)

- Easier metadata entry: Access Services staff will be transitioning from using Excel spreadsheets for metadata entry to CONTENTdm Project Clients. Although this will take some additional training, it will ultimately save time and effort by centralizing all digital object storage and cataloging.

- Expanding this pilot project to include staff from other units within the library, if interest is shown among faculty, staff, and supervisors.

- Continued training and skill development in subject analysis, authority control, and digitization. As staff members express interest in learning more about digital project, the digital archivist continues to hold individual and group training sessions focusing on specific activities and areas of research and practice.
- Document and share the process with others through publicity and publishing. ${ }^{2}$

We are continuing to refine and improve this cross-departmental collaborative process. We hope to use this as a model for other innovative, exciting cooperative projects within the library and possibly beyond the library walls.

\section{Notes}

1. "About UNC Charlotte," University of North Carolina, accessed July 18, 2011, www. uncc.edu/landing/about.

2. The J. Murrey Atkins Library maintains a wiki in order to share training materials with staff and to document and share procedures with other libraries at http://atkinsspecialcollections.pbworks.com/. n 